\title{
Jean-Jacques Hamm, Approches de Stendhal
}

Paris, Classiques Garnier, coll. «Études romantiques et dixneuviémistes ", 2018, 361 p.

\section{Catherine Mariette}

\section{OpenEdition}

\section{Journals}

\section{Édition électronique}

URL : http://journals.openedition.org/recherchestravaux/1146

DOI : 10.4000/recherchestravaux.1146

ISSN : 1969-6434

Éditeur

UGA Éditions/Université Grenoble Alpes

\section{Édition imprimée}

ISBN : 978-2-37747-065-5

ISSN : 0151-1874

Référence électronique

Catherine Mariette, " Jean-Jacques Hamm, Approches de Stendhal », Recherches \& Travaux [En ligne], 93 | 2018, mis en ligne le 01 novembre 2018, consulté le 25 septembre 2020. URL : http://

journals.openedition.org/recherchestravaux/1146; DOI : https://doi.org/10.4000/recherchestravaux. 1146

Ce document a été généré automatiquement le 25 septembre 2020.

(c) Recherches \& Travaux 


\section{Jean-Jacques Hamm, Approches de Stendhal}

Paris, Classiques Garnier, coll. « Études romantiques et dixneuviémistes ", 2018, 361 p.

\section{Catherine Mariette}

\section{RÉFÉRENCE}

Jean-Jacques Hamm, Approches de Stendhal, Paris, Classiques Garnier, coll. «Études romantiques et dix-neuviémistes », 2018, 361 p.

1 Jean-Jacques Hamm a réuni sous le titre Approches de Stendhal la plupart des contributions qu'il a publiées entre 1985 et 2012 dans des revues spécialisées, remaniées pour l'occasion - et dont certaines sont inédites. Les textes sélectionnés ont été regroupés sous quatre rubriques : une première partie chronologique, " CEuvres », rassemble des études sur la création stendhalienne dans une perspective diachronique et fait voir ce qui, des premiers balbutiements en 1797, des «ratages» (p. 20) de l'auteur en herbe, conduit à l'œuvre proprement dite : ou comment Henri Beyle est devenu Stendhal, en faisant l'«apprentissage d'une liberté»(p.147), à travers des constantes nommées «indices» ou « invariants textuels» (p. 12). Ces premiers textes lacunaires ou incomplets de Stendhal permettent à l'auteur de l'ouvrage de dégager, dès le seuil, les premiers éléments d'une poétique de l'inachevé qui a fait la matière d'un livre fondamental et sa signature (Le texte stendhalien : achèvement et inachèvement, Sherbrooke, 1986). Jean-Jacques Hamm échappe ainsi à une perspective purement téléologique et revient d'ailleurs, à la fin de cette première section, sur l'inachèvement pour proposer de le repenser à nouveaux frais, en une sorte de bilan sur la question après les synthèses proposées, depuis la parution de son livre, par Michel Crouzet et Philippe Jousset. L'inachèvement n'est pas considéré comme un échec et « les raisons des inachèvements changent à mesure que l'auteur vieillit » (p. 149). Cette première partie s'intéresse à Stendhal « en tout genre », au fur et à mesure des choix génériques 
de l'écrivain qui suivent la courbe de sa vie : théâtre, journal de voyage, essai sur l'amour, autobiographie, roman (La Chartreuse de Parme), texte hybride et singulier des Privilèges. La deuxième partie, thématique - et qui n'échappe pas à une certaine dispersion -, s'intéresse à des objets aussi divers que la religion, la chasse, les « bois et forêts ", le rapport entre économie politique et roman ou encore le bon usage de la biographie pour éclairer le texte stendhalien («texte et auteur»), en une sorte de « retour à l'auteur » qui n'est pas étranger aux questions que se pose la critique à ce moment-là (l'article date de 2010), après des années de formalisme auquel Jean-Jacques Hamm n'a pas été tout à fait insensible en son temps. L'« auteur » est, dans cet esprit, une construction textuelle, et même si les réticences sont grandes à "remonter le courant vers Beyle» (p. 251), il se dégage de ce très bel article, plus subjectif que les autres sans doute, une figure très touchante de ce sujet-Beyle considéré « au delà de ses masques" comme "un homme engagé dans un combat secret, un homme aussi profondément marqué de solitude » (ibid.). Ces remarques sont toujours fondées sur un examen très attentif du texte stendhalien et partent de l'œuvre pour éclairer la biographie (et non l'inverse) parce que « la biographie peut difficilement accéder à ce que l'auteur cache ». C'est ainsi que la " démarche archéologique » est privilégiée, au détriment de la "causalité psychologique» et que l'inachèvement, revisité une nouvelle fois à l'aune de ces principes, est une " manière d'être » (p. 252), « un habitus stendhalien » (p. 254). Depuis la typologie un peu sèche des premiers textes sur le sujet - mais nécessaire pour cerner la notion et conforme à l'esprit du temps -, l'inachèvement devient une sorte d'anthropologie et il est la mesure à laquelle s'estime et se mesure le parcours de Jean-Jacques Hamm. Enfin, une troisième partie, intitulée "Écriture ", s'intéresse aux pas de côtés de l'écriture stendhalienne, que ce soit le masque, l'écart, le déplacement ("jeux et enjeux de l'épigraphe chez Stendhal »), la "dénégation », la « réticence » ou la « langue sacrée » qui réserve son texte aux initiés choisis, à ces Happy few sur lesquels tant de lignes ont été écrites.

2 Le recueil se clôt sur un article inédit qui sert en quelque sorte de conclusion à l'ensemble («Une autre lecture. Concordances et répétitions ») : d'une part, Jean-Jacques Hamm trace des pistes, des " perspectives ouvertes » sur un sujet actuel, en considérant l'intérêt et les limites de la statistique des textes littéraires, d'autre part, en une sorte de bilan de son parcours de chercheur, il réfléchit sur sa propre pratique des outils informatiques appliqués à la littérature (il est l'auteur d'une table de Concordances des Romans et Nouvelles en quinze tomes, parus de 1991 à 2005 chez Georg Olms Verlag).

Ce volume de synthèse retrace donc l'itinéraire d'un chercheur dont le questionnement est sans cesse en éveil et qui n'hésite pas à revenir sur certaines propositions autrefois énoncées et à les nuancer, à les moduler. Mais la démarche reste essentiellement orientée vers une poétique diachronique des textes, genre et statut confondus, dans le sillage de Gérard Genette et de Jean-Pierre Richard (pour l'aspect thématique de son travail): il s'agit de "dégager des invariants textuels ou un ensemble de figures dominantes exemplaires" (p.12). Malgré ce credo textualiste annoncé dès l'introduction, qui occulte largement le contexte particulier dans lequel a vécu l'auteur, certaines échappées récentes ouvrent le propos sur un Stendhal plus humain et plus incarné. Jean-Jacques Hamm affirme, lui aussi, comme Gérard Genette ${ }^{1}$, que, chez Stendhal, tout est à lire, l'œuvre étant « comme un continent, un archipel de textes, un vaste chantier où l'auteur se mesure à différentes matières, à différents genres, sans jamais choisir la clôture définitive d'une identité unique» (p.11). Le corpus de cet 
ouvrage reprend donc l'ensemble de la production stendhalienne, et c'est l'« œuvre » dans son entier, par-delà les distinctions de genre et d'époque, que croise l'auteur de ce recueil reconstituant un cheminement (le sien propre mais aussi celui de Stendhal) en constante évolution. Même si l'ensemble n'échappe pas à certaines redites, inévitables dans ce genre de florilège, il donne une bonne idée de la variété des sujets qu'a traités Jean-Jacques Hamm tout au long de sa carrière et de son long compagnonnage avec un auteur qu'il connaît parfaitement. On a donc là un livre très stimulant et construit de manière critique, n'hésitant pas à revenir sur des idées jadis énoncées, en un « entretien infini » (p. 11) avec l'auteur d'élection.

\section{NOTES}

1. Gérard Genette écrivait déjà en 1969 que « le texte stendhalien, marges et bretelles comprises est un » («Stendhal », dans Figures II, Paris, Seuil, 1969, p 169).

\section{AUTEURS}

\section{CATHERINE MARIETTE}

Université Grenoble-Alpes / CNRS, Litt\&Arts UMR 5316 